\title{
REFLEXÕES ACERCA DO CORPO E DA SEXUALIDADE DA MULHER NA DANÇA ORIENTAL: COMPARATIVOS ENTRE BRASIL-EGITO SOB A ÓTICA FOUCAULTIANA
}

\author{
REFLEXIONES SOBRE EL CUERPO Y LA SEXUALIDAD DE LAS MUJERES EN LA \\ DANZA ORIENTAL: COMPARACIONES ENTRE BRASIL-EGIPTO A PARTIR DE LA \\ ÓPTICA FOUCAULTIAN
}

\begin{abstract}
REFLECTIONS ABOUT WOMEN'S BODY AND SEXUALITY IN EASTERN DANCE: COMPARATIVES BETWEEN BRAZIL-EGYPT UNDER FOUCAULTIAN OPTICS
\end{abstract}

\author{
Solange Aparecida de Souza MONTEIRO ${ }^{1}$ \\ Vanessa Cristina SCARINGI ${ }^{2}$
}

RESUMO: A arte se classifica por meio dos tempos, desde os mais remotos, nas mais distintas características artísticas, como forma de se olhar o mundo. Dentre as artes mais apreciadas, a arte da dança, presente desde as mais antigas civilizações, perdura nos tempos modernos, encantando gerações. Por meio da dança, seja qual for o estilo, fala-se, escreve-se, desenha-se, sonha-se, utilizando o corpo. A arte da dança potencializa as experiências corporais nas diferentes organizações sociais. A sua importância se faz vigente em cada época da história e é tão singular que se modifica e se transforma, seguindo presente desde as mais antigas civilizações. Pretende-se oportunizar ao sujeito no campo das sensibilidades, a partir da dança, permitindo-o a vivenciar uma experiência cognitiva/afetiva proporcionando disrupção no modo de ler/pensar e agir, sobre si, o outro e o mundo de forma ética e reflexiva. Deste modo, a referente pesquisa qualitativa buscou analisar as semelhanças e diferenças do corpo e da sexualidade da mulher na dança oriental no Brasil e no Egito por meio da análise temática. Os resultados esperados sinalizam para uma melhoria dos modos de dançar de forma prazerosa e crítica com maior envolvimento emocional, sinalizam a criação do ambiente de espontaneidade e criatividade permitindo-o a se embrenhar pela linguagem corporal, possibilita construção e reconstrução do olhar, a estimulação da imaginação, autoafirmação e autonomia, além de se habituar à existência de convivência de forma. Nesse sentido, a arte pode ser inovadora ao se desdobrar para um projeto de vida, na (re)construção de novas subjetividades, impactando novos modos de existência.

PALAVRAS-CHAVE: Corpo. Dança. Poder. Sexualidade.

RESUMEN: El arte se clasifica a través de las edades, desde las más remotas, en las características artísticas más distintas, como una forma de mirar el mundo. Entre las artes más apreciadas, el arte de la danza, presente desde las civilizaciones más antiguas, perdura en los tiempos modernos, encantando a generaciones. A través de la danza, sea cual sea el estilo,

1 Universidade Estadual Paulista (UNESP), Araraquara - SP - Brasil. Doutoranda em Educação Escolar. Integrante do Núcleo de Estudos da Sexualidade (NUSEX). ORCID: http://orcid.org/0000-0002-1640-0266. Email: sol47monteiro@gmail.com

${ }^{2}$ Prefeitura Municipal de Rio Claro, Rio Claro - SP - Brasil. Professora de Ensino Fundamental I. Mestrado em Educação (UNESP). ORCID: https://orcid.org/0000-0002-7305-366X. E-mail: vcscaringi@ymail.com 
hablamos, escribimos, dibujamos, soñamos, usando el cuerpo. El arte de la danza potencia las experiencias corporales en diferentes organizaciones sociales. Su importancia está presente en cada época de la historia y es tan singular que se modifica y transforma, estando presente desde las civilizaciones más antiguas. Se pretende dar al sujeto la oportunidad en el campo de las sensibilidades, desde la danza, permitiéndole vivir una experiencia cognitivo / afectiva aportando disrupción en la forma de leer / pensar y actuar, sobre sí mismo, el otro y el mundo de forma ética y reflexiva. . De esta manera, la investigación cualitativa referente buscó analizar las similitudes y diferencias del cuerpo y la sexualidad de la mujer en la danza oriental en Brasil y Egipto a través del análisis temático. Los resultados esperados señalan una mejora en las formas de bailar de manera placentera y crítica con mayor implicación emocional, señalan la creación de un ambiente de espontaneidad y creatividad que le permite involucrarse con el lenguaje corporal, posibilitar la construcción y reconstrucción de la mirada, la estimulación de imaginación, autoafirmación y autonomía, además de acostumbrarse a la existencia de la coexistencia de formas. En este sentido, el arte puede ser innovador cuando se despliega en un proyecto de vida, en la (re) construcción de nuevas subjetividades, impactando nuevos modos de existencia.

PALABRAS CLAVE: Cuerpo. Danza. Poder. Sexualidad.

ABSTRACT: Art is classified through the ages, from the most remote, in the most distinct artistic characteristics, as a way of looking at the world. Among the most appreciated arts, the art of dance, present since the earliest civilizations, endures in modern times, enchanting generations. Through dance, whatever the style, one speaks, writes, draws, dreams, utilizing the body. The art of dance enhances bodily experiences in different social organizations. Its importance is in force in every epoch of history and is so unique that it changes and changes, and has been present since the earliest civilizations. The aim is to give the subject the opportunity in the field of sensitivities, based on dance, allowing him to experience a cognitive / affective experience, providing disruption in the way of reading / thinking and acting, about himself, the other and the world in an ethical and reflective way. In this way, the referring qualitative research sought to analyze the similarities and differences of the woman's body and sexuality in oriental dance in Brazil and Egypt through thematic analysis. The expected results signal an improvement in the ways of dancing in a pleasurable and critical way with greater emotional involvement, signaling the creation of an environment of spontaneity and creativity, allowing it to immerse itself in body language, enabling the construction and reconstruction of the gaze, the stimulation of the body. imagination, self-affirmation and autonomy, in addition to getting used to the existence of coexistence of form. In this sense, art can be innovative as it unfolds into a life project, in the (re) construction of new subjectivities impacting new modes of existence.

KEYWORDS: Body. Dance. Power. Sexuality.

\section{Introdução}

A arte é um elemento importante para a reconfiguração da vida. A arte faz parte de um processo criativo que permite ao/à praticante a reinvenção de si e do mundo que os/as cerca. 
Gombrich (2000, p. 15) menciona sobre arte, "muitas pessoas gostam de ver o que também lhes agradaria ver na realidade", mas "o problema é que gostos e padrões variam imensamente".

Sendo assim, pode-se dizer que a arte, nos mais diferentes estilos - música, dança, culinária, poesia, entre outras, existem para nos apresentar, nos causar desordem, desproporção, nos ausentar de regularidades, criações, movimentos outros. Deleuze (1983) referencia que

se os estados de coisas tornam-se movimento de mundo, se os personagens tornam-se figura de dança [...] a dança, o balé, a mímica abandonavam as figuras e as poses para liberar os valores não posados, não pulsados, que reportavam o movimento ao instante qualquer.

A utilização da dança seria apenas uma (re)vestimenta de um poder em relação ao corpo e à sexualidade?

No entanto, a arte da dança pode ser instrumento para promoção de leituras mais profundas do jogo poder (re)significar sua vida, o mundo que o rodeia e a si próprio. A partir destes questionamentos se propõe a lançar um olhar em uma temática cara aos dias atuais a sexualidade e a constituição de subjetividades por meio das linguagens, do discurso, dos códigos, da dança, das tecnologias.

Sendo assim, dentre as artes mais apreciadas, a arte da dança, presente desde as mais antigas civilizações, perdura nos tempos modernos, encantando gerações. A arte da dança potencializa as experiências corporais nas diferentes organizações sociais. A sua importância se faz vigente em cada época da história e é tão singular que se modifica e se transforma, seguindo presente desde as mais antigas civilizações, é um dispositivo que possibilita o funcionamento de tecnologias de si, nos moldes foucaultianos que podem levar o educando a um processo de cuidado de si na construção ética de sua existência.

Nos primórdios, dançava-se para celebrar o nascimento e até mesmo para se comunicar com forças sobrenaturais. Era uma forma de expressão dos sentimentos, das emoções e dos pensamentos. Supõe-se que a dança era utilizada como ritual para reverenciar o nascimento, festejar o sucesso nas caças ou mesmo como lamento às mortes durante as lutas entre os povos. Os povos que viveram acerca de 15.000-10.000 anos antes do período cristão, deixavam os seus registros gravados em pedras naturais nas paredes das cavernas. São pinturas rupestres encontradas por arqueólogos em todos os continentes.

No Brasil, por exemplo, ainda é possível contemplar amostras da arte rupestre na Fundação Museu do Homem Americano (Fumdham) no Parque Nacional da Serra da Capivara, localizada em Piauí, sustentado por anos pela Lei Federal de Incentivo à Cultura, conhecida popularmente como Lei Rouanet (BRASIL, 1991). 
Já na Antiguidade, a dança apresentava características sagradas em meio ao caráter divino. Nas paredes dos templos egípicios ainda é comum encontrar resgistros de bailarinas durante a manifestação de adoração às divindades da época. A imagem do papiro egípcio exposta na figura 1 demonstra o quão importante a arte na vida diária dos povos do antigo Egito. Alguns instrumentos musicais como flauta, harpa e alaúde eram normalmente utilizados em festas religiosas, acompanhados de muitas danças.

Figura 1 - Pintura em papiro egípicio intitulada Três Dançando Música.

Fonte: acervo das autoras

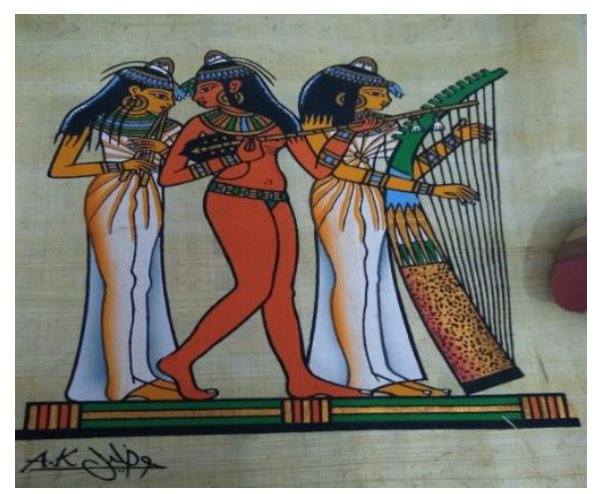

Havia uma composição artística para o início de um ritual "acompanhado por músicos, dança e canto" em que "o som purificava o astral, o canto louvava a vida... a dança era expressão corporal e anímica dos sentimentos, dos desejos" (MIEL, 2019, p. 103) em que mais uma vez a dança aparece como personificação da realidade, dos sonhos e dos anseios da humanidade.

Assim ocorreu também na Índia e na China em que as danças inspiravam as manifestações das crenças por meio dos movimentos corporais. Na Grécia, além do caráter divino, foi utilizada para tornear corpos dos soldados que deviam também aprender a dançar afim de harmonizar corpo e alma.

Por outro lado, na Idade Média, período marcado pela ascensão do cristianismo, iniciase um movimento que coloca a dança como profana, praticada apenas por camponeses. $\mathrm{O}$ distancimento das crenças possibilitou maior participação popular na arte da dança.

No entanto, o sentimento de culpa começa a se introjetar durante o Renascimento e a intolerância religiosa deu ao corpo dançante o misticismo de puní-lo como pagão, considerando as manifestações corporais como pecado.

Assim, a dança popular ressurge durante o Renascimento com formas estilizadas. Daí então, apreciada também pela nobreza como entretenimento durante as festas da corte, simbolizando o poder com o luxo e a ostentação de figurinos nas apresentações coreografadas dos balés palacianos. 
Pode-se pensar que a construção da identidade é advinda das relações singulares estabelecidas em decorrência das experiências vivenciadas, da história pessoal de cada um e do(s) outro(os) que constitui o sujeito, implicando-o a todo momento, frente ao estranhamento, ao diferente, em dar novos sentidos, deslocando-o, possibilitando a (re)significar seu modo de existência e suas subjetividades. Sendo assim, podemos considerar que, por meio da dança, o sujeito poderá se reavaliar e talvez revelar em um outro sujeito mais autêntico de si, reconstituído de identidades, subjetividades e singularidades outras.

É a possibilidade de modificar com suas ações, as ações opostas presentes no outro, formas pelas quais as práticas discursivas e não discursivas, ora pelos discursos que se é obrigado a produzir, ora pelos movimentos dos quais se tornam vitimados pela própria organização que a acomete, por vezes, sem a devida consciência e reflexão. São formas pelas quais a sociedade se coloca e se movimenta, reis e súditos, leis que operam, quem as determinam e os que devem obedecer

para assinalar simplesmente, não o próprio mecanismo da relação entre poder, direito e verdade, mas a intensidade da relação e sua constância, digamos isto: somos forçados a produzir a verdade pelo poder que exige essa verdade e que necessita dela para funcionar, temos de dizer a verdade, somos coagidos, somos condenados a confessar a verdade ou encontrá-la (FOUCAULT, 1987, p. 29).

Na transição para a Modernidade, outras intenções se firmaram na dança. A dança rompeu com o previsível, modificando-se em meio a intensas experimentações. O bailarino brasileiro Vianna (2005, p. 41) menciona de forma inspiradora que "não é só dançar, é preciso toda uma relação com o mundo a nossa volta", reconhecendo o corpo na arte da dança como movimento criativo.

Os apaixonantes movimentos dançantes que encantavam gerações abrem espaços para novas possibilidades de criação, outros modos de existência, devires-dança. Menciona Deleuze (1983, p. 16) que "o todo se cria e não para de se criar numa outra dimensão sem partes, como aquilo que leva o conjunto de um estado qualitativo a outro, como o puro devir incessante que passa por esses estados" que envolvem, afetam, aprisionam ou libertam e permitem que a linguagem permaneça e funcione.

A dança, enquanto "arte dos movimentos corporais perde-se na história mais longínqua da humanidade" (DOURADO, 2004, p. 103), torna possível um processo artístico que ocasiona aos sujeitos possibilidades outras de desvendar os mistérios do mundo e transformarem-se com 
ou por ela. Por meio da dança, seja qual for o estilo, fala-se, escreve-se, desenha-se, sonha-se, educa-se utilizando o corpo.

E dentro desta ampla relação com a Educação em que corpos se educam, são educados e educam outros corpos, a referente pesquisa qualitativa buscou analisar as semelhanças e diferenças do corpo e da sexualidade da mulher na dança oriental no Brasil e no Egito por meio da análise de sentidos. Esse tipo de abordagem se alimentou de dados desde as experiências individuais ou coletivas quanto discursos, desenhos, fotos, narrativas, documentos, observações, trazidos posteriormente. As categorias de modelo corporal na dança foram analisadas para mostrar a sua evolução no tempo e em diferentes espaços e as diferentes formas que se educam corpos na arte da dança.

\section{De raqs shark à dança do ventre}

Pautando-se nas experiências do passado em consonância com o presente, despontou no Brasil, por volta da década de 1950, a raqs sharqi (dança oriental) mencionada pela palestina Sharkey $(2002$, p. 6) como a dança do leste "onde o sol nasce e de onde a mulher recebe as energias do sol".

Conta-se que por volta de 7.000 anos anteriormente ao cristianismo, nos países árabes (Egito, Líbano, Síria, Marrocos, entre outros), a dança oriental era executada por mulheres, as sacerdotisas. Essas ofereciam os movimentos dançantes a Ísis - deusa do ventre fértil, a grandedeusa. Dentre os aspectos milenares, esse estilo foi e é marcado por movimentos ondulatórios e batidas de quadril com deslocamentos elegantes por vezes provindos do balé, perpetuando a junção entre passado e presente.

Os praticantes dessa modalidade se referem a dança oriental de forma mais ampla, pois traz características do folclore em fusão com outras culturas bem como o uso de ornamentos como véu, bengala, pandeiro, candelabro, taças, espada, etc.

$\mathrm{Na}$ dança dos sete véus, por exemplo, a bailarina usa o adorno em menção às sacerdotisas em culto a Ísis. Repleta de mistérios, dentre os mitos que circundam sobre o aparecimento desta dança, sejam romanos, gregos ou egípcios, "as divindades aparecem, desaparecem, mudam de nome e de função, segundo as circunstâncias", relata Traunecker (1995, p. 18).

Um dos mitos aproxima os véus às cores do arco-íris "formado pelos raios de sol refletidos na chuva, no qual as cores combinadas onde se juntam parecem a mesma, mas a pequena distância do ponto de contato são inteiramente diferentes" (BULFINCH, 2002, p. 133), 
relacionando-os ao grande astro e aos planetas do Sistema Solar: véu amarelo $=$ Sol (ou Rá deus da luz), véu vermelho $=$ Marte (ou Ares - deus da guerra), véu laranja $=$ Júpiter (ou Zeus - deus dos céus), véu verde = Mercúrio (ou Hermes - deus do comércio), véu azul = Vênus (ou Afrodite - deusa da beleza e do amor), véu lilás = Saturno (ou Cronos - deus do tempo) e véu branco $=$ Netuno (ou Poseidon - deus dos oceanos).

Somente experimentando os sete véus é possível chegar ao portal que guarda a passagem de um mundo para o outro, ou ainda, o entre-mundos da dança como linha de fuga, no qual os sentidos acontecem, manifestando o que deseja fazer com o seu corpo na dança, empoderandose.

Os movimentos simbolizam a fertilidade do ventre, a maternidade dos seios, a entrega do corpo, a alegria dos ombros, tristeza, anseios, pedidos com o dobramento e desdobramento do tronco [...] grados de consciência com as cores" (MIEL, 2019, p. 103).

Acredita-se que as bailarinas do antigo Egito usavam óleo de cobra para tornarem as suas articulações mais flexíveis durante as suas danças acrobáticas. Isso remete ao fato da possibilidade de contorcerem o ventre para todos os lados. Essas bailarinas foram esculpidas nas paredes de muitos templos egípcios como mostra a figura 2 .

Figura 2 - $\mathrm{O}$ ventre das bailarinas contorcionistas retratadas no interior do templo de Luxor.

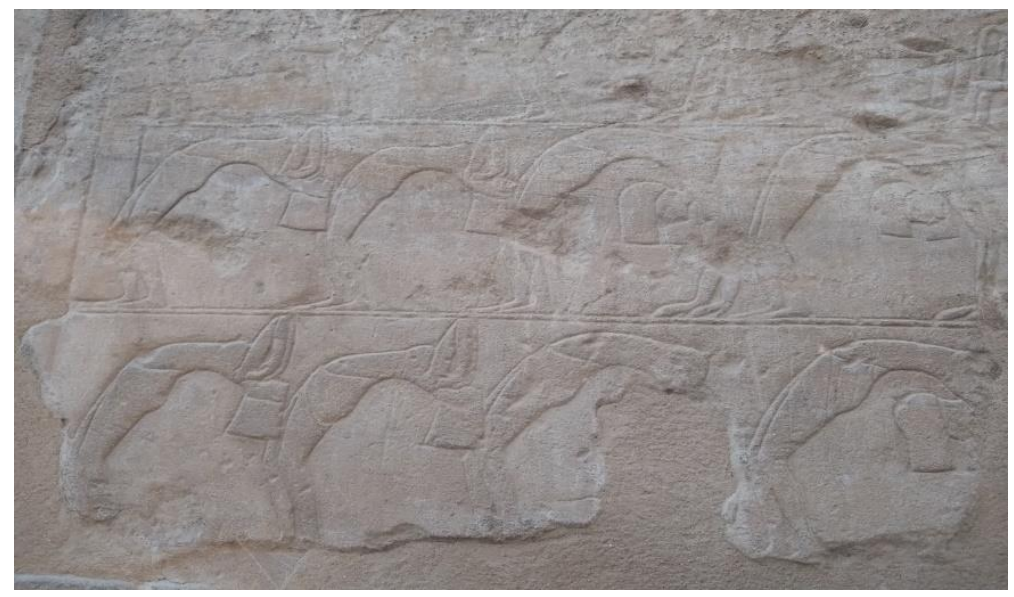

Fonte: acervo das autoras

Embora, na contemporaneidade, com influências das culturas de diferentes países, a dança oriental tenha sofrido mudanças, a sua trajetória histórica está de tal modo vinculada ao imaginário da cultura ocidental e bastante difundida seja pelo cinema, pela televisão ou pela internet. Há bailarinas egípcias que ganharam destaque com suas belas performances: Samia Gamal (Zeinab Ali Khalil Ibrahim Mahfouz, 1924-1994) e Taheyya Kariokka (Badaweya Mohamed Kareem Al Nirani, 1915-1999) que recebeu este nome artístico após o derbakista 
misturar em suas apresentações sons da música árabe aos sons da música brasileira. Na tentativa de se assemelhar aos deuses, bailarinas deixam seus nomes de batismo para incorporarem seus nomes artísticos, talvez, metamorfoseando-se conforme as situações.

No Brasil, o despontar da dança oriental se assemelha à chegada de imigrantes árabes em meados do século XIX. Na década de 1950, a dança oriental foi largamente propagada pela pioneira Shahrazad Sharkey (Madeleine Iskandarian Kitishian, 1940-2014).

Com o decorrer dos anos, a nomenclatura árabe ganhou a definição de dança do ventre e alguns espaços passaram a promover o ensino dessa arte por todo o país, onde simultaneamente acontecem apresentações da dança oriental e suas variações e fusões.

Geralmente, os espaços de apresentação da arte da dança oriental são organizados de forma muito similar e oferecem ambientes de estudo como também ambientes que caracterizam os antigos templos dos faraós, as tendas e os haréns decorados com mobiliários, lustres e paredes pintadas ao estilo faraônico, utilizados durante as apresentações ao público. Nesses ambientes são oferecidos serviços de cafeteria simultaneamente às apresentações de danças.

Esses shows de dança geralmente são ofertados por grupos distintos de bailarinas. Há apresentações de bailarinas iniciantes que ainda estudam a dança oriental num estágio básico de desenvovimento artístico. São orientadas em cursos de formação com bailarinas mais experientes, vistas como divas da dança, deusas ou algo similar. Nestes espaços, degusta-se a arte numa mistura de sensações, saboreando os cardápios e as apresentações das belas mulheres que dançam em espaços que remete ao harém.

Mas por que harém?

No harém dos grandes impérios árabes, por exemplo, as mulheres são mantidas em espaços reservados da casa, onde quem domina é exclusivamente as ordens do sultão - senhor absoluto, poderoso. São minuciosamente escolhidas, ingressando como odaliscas - termo provindo do turco odalyk que, segundo o dicionário online Michaelis (2009) designa como "mulher do harém do sultão", porém trocando os seus nomes próprios por nomes persas a fim de enaltecer suas qualidades, prática ainda adotada pelas grandes bailarinas da dança oriental pelo mundo.

O dicionário online Michaelis (2009, grifo nosso) exprime o significado da palavra harém, do árabe haram, como

1 Parte da casa muçulmana destinada às mulheres. 2 Conjunto de mulheres legítimas, concubinas, parentas e serviçais de uma casa muçulmana. 3 Zool Grupo de fêmeas associadas com um só macho. 4 Lupanar. 
Considerando que a última expressão dada pelo dicionário está associada à casa de prostitutas, dessa forma, diferentes sentidos perpassam entre o real e o imaginário sobre bailarinas da dança oriental que são comumente confundidas com odaliscas.

Giffoni (1974) cita a dança das odaliscas como "finalidade social”, pois, uma vez no harém, à disposição da mulher do sultão, aprendem a dançar, recitar poemas e quem sabe tornarse sultana, a favorita do sultão, indo de encontro às relações entre sexualidade e poder que Foucault (1987 p. 133) estabelece como "relações produtivas" e que entrelaçam tantas histórias na sociedade.

\section{Corpos, sexualidade e poder: dança-devir}

A dança é a arte que coloca o corpo em movimento, demonstrando, por meio do corpo, as diferentes formas que a sociedade se organiza.

O papel das artistas da dança na sociedade, tanto no Egito como no Brasil, carregam semelhanças aos olhares masculinos. Recebem propostas de shows privados que sugerem à prostituição mesmo por vezes não exercendo tal atividade paralela.

Ambos os países apresentam semelhanças na forma de manifestação do corpo da mulher por meio da arte da dança; as casas de shows tanto egípicias como brasileiras apresentam a imagem dos corpos das bailarinas também como produto comercializado.

Embora a dança oriental esteja vinculada à imagem erotizada da mulher e ainda seja prática corriqueira, em países árabes, colocar dinheiro na roupa da bailarina após uma apresentação de dança, ressalta Sharkey (2002, p. 5-6) que "uma bailarina não deve aceitar que os homens coloquem dinheiro no seu corpo. Eles dizem que é costume, mas isto não é verdade. O corpo da mulher é sagrado e o povo deve assistir a essa dança com muito respeito e admiração".

Dessa forma, Foucault (1987) apresenta o poder como uma correlação de forças que dá forma à maneira com a qual um indivíduo age sobre a ação de um ou mais indivíduos e, ainda, sobre a maneira como age sobre si mesmo. O exercício do poder consiste em pôr em ação mecanismos de poder.

Os mecanismos de poder são constituídos por tecnologias específicas para cada objetivo desejado. Por exemplo, em Vigiar e Punir, Foucault (1987) descreve em detalhes as técnicas disciplinares com o objetivo de mostrar o processo de domesticação dos corpos e mentes dos indivíduos. Instituições diversas, como a escola, hospitais, quartéis e prisão desenvolveram mecanismos, a partir do séc. XVII, baseados na vigilância ininterrupta e no controle do 
comportamento individual em seus ínfimos detalhes. Por exemplo o poder pastoral, exerce uma técnica de controle e de direção da consciência, a qual consistia em incitar os indivíduos a falarem de si, a confessarem o mais íntimo de si.

Ao ser colocada em prática tal poder, instituições como a Igreja, a família, instituições educativas, artísticas e médicas, intensificam o controle sobre os indivíduos não somente por meio da objetivação de seus comportamentos, mas também, a partir daquilo que constitui a subjetividade desses indivíduos. A verdade não existe fora do poder ou sem o poder. A verdade é deste mundo; ela é produzida nele graças a múltiplas coerções e nele produz efeitos regulamentados de poder (Foucault, 1987, p. 12).

No Egito, após a primeira menstruação, as mulheres utilizam lenço para cobrir os cabelos. Todo o corpo da mulher necessita se manter escondido em meio a roupagem com muito tecido fato que diferencia das artistas da dança as quais parecem obter licença na arte para apresentar o corpo da forma que desejam.

O corpo mostra "o papel que nele desempenham as representações, as crenças, os efeitos de consciência" (CORBAIN et al., p. 8) e essas representações definem a sexualidade.

O poder tem importância na representação do corpo e da sexualidade da mulher porque, assim como a dança, ele não é estático, é algo que se move. Foucault (2013, p. 89) afirma que “o poder está em toda a parte, não porque englobe tudo e sim porque provém de todos os lugares". O poder se materializa no próprio corpo da mulher por meio da dança com intuito de disciplinar e adestrar a sua própria sexualidade, pois

nas relações de poder, a sexualidade não é o elemento mais rígido, mas um dos dotados de maior instrumentalidade: utilizável no maior número de manobras, e podendo servir de ponto de apoio, de articulação à mais variadas estratégias (FOUCAULT, 2013, p. 98).

E o poder atuante, mutante, instável possibilita sentidos outros. De suas continuidades e rupturas, é a base dos estudos que Foucault (2013) faz quando analisa as relações entre loucura e civilização, ou quando examina a estrutura de conhecimento em uma determinada época. Seu estudos mostram como a produção de verdade acontece no discurso (nas práticas e seus regimes de dizibilidade, visibilidade, dispositivos de saber e poder, etc.). Essa verdade é descontínua e precisa ser incessantemente retomada e revisada, pois a história das descontinuidades, ensina Foucault (1987), não se adquire de uma vez por todas; ela é impertinente por si mesma.

Do oriente para o ocidente, a dança oriental também rompeu com o previsível, modificando-se em meio a intensas experimentações. Antes dançada no harém apenas para o sultão (e exclusivamente a ele toda a manifestação erótica e sensual da dança oriental), hoje se 
dança em um harém composto por um público misto e por vezes desconhecido. E os corpos das mulheres dançantes estão subordinados a esse público. Pode-se mencionar que todo esse público heterogêneo inspira a (des)construção dos corpos das mulheres que dançam.

Menciona Deleuze (1983, p. 16) que "o todo se cria e não para de se criar numa outra dimensão sem partes, como aquilo que leva o conjunto de um estado qualitativo a outro, como o puro devir incessante que passa por esses estados" que envolvem e afetam. No devir-dança, cada criação permite um contágio, outra dança como modo de experimentar a vida. Se para Deleuze e Guattari (2017, p. 67) "todo devir é minoritário", a sexualidade da mulher que perpassa na dança do ventre é um devir, pois todo devir é uma conexão.

O devir-dança pode seguir capturado pelo poder ou transgredi-lo. Para Furlani (2016, p. 62), “à medida que as mulheres se autorrepresentam [...] estabelece-se um processo cultural de desconstrução dos conceitos negativos que marcam as mulheres como "inferiores, subordinadas" (FURLANI, 2016, p. 62) e nesse sentido o devir-dança possibilita uma desconstrução de processos que implicam à sexualidade das mulheres para outros entendimentos, para o empoderamento.

Assim sendo, escrever sobre sentidos outros na dança oriental permite perpetuar informações significativas sobre o corpo e a sexualidade da mulher na sociedade como também desvelar o que não é imediatamente visível nem se quer absolutamente oculto, mas que está lá, no recuo, na pausa, no entre, no instante.

A dança é um caminho que nos coloca em conexão com o mundo que nos cerca e dessa forma nos educa. Como sugere o termo, toda $(\mathrm{mu})$ dança traz na dança a possibilidade de transformação, de ampliação do conhecimento, de movimentos outros que promovem a aprendizagem de diferentes formas de se posicionar frente à vida porque emancipa ao passo que proporciona mudanças significativas para a ampliação do conhecimento em relação ao corpo físico, psíquico, contribuindo para avanços sócio-culturais.

Como exemplo, atualmente, diversas bailarinas egípicias foram à ruas da cidade do Cairo se manifestarem por meio da dança contra o assédio sexual que segue em alta no Egito, segundo dados da ONU (2013). O projeto ficou conhecido como Ballerinas of Cairo, registrado pelo fotógrafo Mohamed Taher em contraposição às falas masculinas que sugerem que as mulheres permaneçam dentro de suas casas.

Este espaço, o do discurso, é posto em causa sistematicamente em cada prática discursiva realizada, principalmente na pesquisa. Ainda, conforme Maingueneau (2015, p. 31): 
[...] o "discurso" não é apresentado como um território circunscrito, mas como um espaço incerto entre dois maciços, lá onde se "desfazem os laços aparentemente tão fortes entre as palavras e as coisas", entre a linguagem e o mundo. A proliferação incontrolável da noção de discurso aparece como sintoma de uma abertura, nas últimas décadas do século XX, desse espaço incerto.

Portanto, é desse lugar em que se encontram e se atravessam as linhas teóricas propostas aqui, em relação as questões da língua, da história e do sujeito, que encaminha-se a pesquisa. Os estudos foucaultianos, como já abordados, são interdisciplinares, utilizando-se de várias áreas do conhecimento como a filosofia, a linguística, a arte, a história entre outras.

Considera-se, assim que é preciso superar a disciplinaridade (Sociologia), dialogar com a interdisciplinaridade (Educação Escolar) e, até no limite, com a anti-disciplinaridade (Estudos Culturais). Procurar ultrapassar esses campos, ressignificando-os, é utilizar a antidisciplinaridade $(\mathrm{AD})$ não simplesmente como uma "[...] caixa de ferramentas no vasto conjunto dos 'métodos qualitativos' das ciências sociais e humanas", como expõe o analista do discurso Maingueneau (2015, p. 32), mas como uma teoria que dialoga com outras teorias durante todo o percurso desse trabalho e não somente no momento final, nas análises.

Desta maneira, a AD constitui-se também a postura desse sujeito-pesquisador em relação a essa tese. E mais ainda, Orlandi (2012, p. 26), considera que a análise do discurso não quer deter-se a uma "verdade", mas procura construir dispositivos analíticos e metodologias para que o analista identifique "gestos de leitura" e os compreenda a partir de seu dispositivo. Para a análise dos discursos, o dispositivo construído tem, em sua base, pressupostos dos estudos discursivos foucaultianos (FOUCAULT 1987, 2013), e da relação da mídia com o discurso (GREGOLIN, 2001; CHARAUDEAU, 2006). Da mesma maneira em que houve a construção de um método para essa tese, o dispositivo analítico da AD também se constrói, utilizando-se de uma práxis constante, à medida em que se desenvolve a análise na prática, busca-se à teoria e vice-versa.

\section{Considerações finais}

Atualmente, a dança, em seus mais variados estilos, ganha espaço na vida social. A dança oriental é um exemplo. Com estilo genuinamente feminino, cada vez mais mulheres procuram praticá-la. Está em expansão no território nacional e mundial. O corpo da mulher ocupa papel central neste estilo artístico e passa por um processo educativo que auxilia no empoderamento. Baseado nesta circunstância, os espaços que promovem a dança oriental propõe em sua publicidade um corpo dançante livre e conectado com sua sexualidade. Então, 
mulheres que praticam a dança oriental têm a possibilidade de conectar vivências e experiências à sua sexualidade.

Assim como mudam-se os movimentos, muda-se o poder. O poder, que da mesma forma atua sobre esses corpos, permite, por meio da representação da mulher na dança oriental, pensar outras formas de devir a própria sexualidade.

Isso demonstra que, embora determinados acontecimentos influenciam no controle dos desejos e das emoções, fruto das relações de poder, associados a um corpo sexualmente erótico que necessita de uma orientação ética, o corpo da mulher encontra na dança espaços outros para manifestar a sua liberdade.

\section{REFERENCIAS}

BRASIL. Lei n. 8.313, de 23 de dezembro de 1991. Lei Federal de Incentivo à Cultura. Restabelece princípios da Lei n. 7.505, de 2 de julho de 1986, institui o Programa Nacional de Apoio à Cultura (Pronac) e dá outras providências. Brasília, 24 dez. 1991. Disponível em: http://www.planalto.gov.br/ccivil_03/leis/18313cons.htm. Acesso em: 12 de fev. 2018.

BULFINCH, T. O livro de ouro da mitologia: história de deuses e heróis. Trad. David Jardim Jr. Rio de Janeiro: Ediouro Publicações, 2002.

CHARAUDEAU, P. Discurso das mídias. São Paulo: Editora Contexto, 2006.

CORBAIN, A.; COURTINE, J.; VIGARELLO, G. História do corpo: da renascença às luzes. Rio de Janeiro: Editora Vozes, 2008.

DELEUZE, G. A imagem-movimento. Trad. Stella Senra. São Paulo: Editora Brasiliense, 1983.

DELEUZE, G.; GUATTARI, F. Mil platôs. Trad. Peter Pál Pelbart e Janice Caiafa. São Paulo: Editora 34, 2017.

DOURADO, H. A. Dicionário de termos e expressões da música. São Paulo: Ed. 34, 2004.

FOUCAULT, M. História da sexualidade 1: a vontade de saber. Trad. Maria Thereza da Costa Albuquerque. São Paulo: Editora Paz e Terra, 2013.

FOUCAULT, M. História da sexualidade 3: o cuidado de si. Trad. Maria Thereza da Costa Albuquerque. São Paulo: Editora Paz e Terra, 2013.

FOUCAULT, M. Vigiar e punir: nascimento da prisão; tradução de Raquel Ramalhete. Petrópolis: Vozes, 1987.

FURLANI, J. Educação sexual na sala de aula: relações de gênero, orientação sexual e igualdade étnico-racial numa proposta de respeito às diferenças. Belo Horizonte: Autêntica Editora, 2016. 
GIFFONI, M. A. C. Danças da Ásia, África e Oceania. São Paulo: Nobel, 1974.

GOMBRICH, E. H. A história da arte. Rio de Janeiro: LTC, 2000.

GREGOLIN, M. R. V. Análise do discurso: os sentidos e suas movências. In: GREGOLIN, M. R. V. et al. (org.). Análise do discurso: entornos do sentido. Araraquara: UNESP, Laboratório Editorial; São Paulo: Cultura Acadêmica Editora, 2001.

MAINGUENEAU, D. Discurso e análise do discurso. Trad. Sírio Possenti. São Paulo: Parábola Editorial, 2015.

MICHAELIS. Dicionário de Língua Portuguesa. 2009. Disponível em: http://michaelis.uol.com.br/. Acesso em: 12 de fev. 2018.

MIEL, L. Borbulhas de dança: mundo encantado, estranhos prazeres, profundos conflitos. Santa Catarina: Clube de Autores, 2019.

ORLANDI, E. P. Discurso em Análise: Sujeito, Sentido, Ideologia. Campinas: Pontes, 2012.

SHARKEY, S. Resgatando a feminilidade: expressão e consciência corporal pela dança do ventre. São Paulo: Scortecci Editora, 2002.

TRAUNECKER, C. Os deuses do Egito. Brasília: Editora Universidade de Brasília, 1995.

VIANNA, K. A dança. São Paulo: Summus Editorial, 2005.

\section{Como referenciar este articulo}

MONTEIRO, S. A. S.; SCARINGI, V. C. Reflexões acerca do corpo e da sexualidade da mulher na dança oriental: comparativos entre Brasil-Egito sob a ótica foucaultiana. Rev. Sem Aspas, Araraquara, v. 9, n. 1, p. 156-169, jan./jun., 2020. e-ISSN: 2358-4238. DOI: https://doi.org/10.29373/sas.v9i1.14268

Submetido em: 10/03/2020

Revisões requeridas: 20/05/2020

Aprovado em: $31 / 07 / 2020$

Publicado em: 30/09/2020 